\title{
Efficacy of doxycycline as a combination therapy in the treatment of rheumatoid arthritis: a randomized controlled clinical trial
}

\author{
Eman M. Ibrahem ${ }^{1^{*}}$ (D), Salwa S. El-gendi ${ }^{1}$, Amal A. Mahmoud ${ }^{2}$, Sherif M. Abdel-Aall ${ }^{3}$ and
} Hanan Sharaf El-Deen Mohammed ${ }^{1}$

\begin{abstract}
Background: This single-center randomized open-label clinical trial evaluates the effectiveness of doxycycline as a combination therapy for active rheumatoid arthritis (RA) with methotrexate (MTX).

Materials and methods: One hundred and sixty RA patients were recruited who fulfilled the 2010 American College of Rheumatology/European League Against Rheumatism (ACR/EULAR) classification criteria. Subjects were randomly allocated in a 1:1 ratio into one of two treatment arms; one group was maintained on MTX alone and the other group on MTX together with doxycycline orally $200 \mathrm{mg}$ daily. Follow-up clinical response, erythrocyte sedimentation rate (ESR), levels of C-reactive protein (CRP), and disease activity score 28 (DAS28-CRP) after 3 months were done.

Results: There was a significant difference regarding DAS28-CRP between the two groups (median (IQR) 4.26 (3.65) for those treated with MTX alone compared with 2.8 (2.37-3.5) for those treated with MTX together with doxycycline) $(p=0.005)$. A higher number of patients treated with doxycycline in combination with MTX achieved remission (40.5\%) compared to patients who received MTX alone (13.5\%). The levels of ESR and CRP were lower in patients treated with MTX and doxycycline and this was statistically significant ( $p=0.005, p=0.003$ respectively).

Conclusion: Doxycycline as a cost-effective combination therapy with MTX can achieve higher rates of remission than MTX alone in RA patients without causing increase in the adverse events profile.
\end{abstract}

Trial registration: Clinical Trials.gov, NCT03194204. Registered on 21 June 2017

Keywords: Rheumatoid arthritis, Randomized controlled trial, Combination therapy, Cost-effective, Doxycycline

\section{Background}

Rheumatoid arthritis (RA) primarily affects the synovial joints and causes systemic chronic inflammation. When left untreated, it results in joint damage which is responsible for the deformity and disability found in this disease [1]. The earliest phase in RA is possibly the

\footnotetext{
* Correspondence: emanmibrahem@gmail.com

'Department of Internal Medicine, Rheumatology Unit, Faculty of Medicine, Assiut University, Assiut, Egypt

Full list of author information is available at the end of the article
}

activation of innate immunity. A wide variety of jointspecific antigens as type II collagen and non-specific citrullinated antigens are responsible for $\mathrm{T}$ cell activation [2]. Cytokines generated by these activated $\mathrm{T}$ cells promote chronic inflammatory processes [3]. Among these are interleukin (IL)-1, tumor necrosis factor-alpha (TNF$\alpha)$, IL-6, IL-8, destructive enzymes such as collagenase and stromelysin [4] in addition to, IL-18 which induces release of interferon-gamma (IFN- $\gamma$ ) and upregulates nitric oxide synthetase and cyclooxygenase (COX)-2 [5].

\section{Springer Open}

(-) The Author(s). 2021 Open Access This article is licensed under a Creative Commons Attribution 4.0 International License, which permits use, sharing, adaptation, distribution and reproduction in any medium or format, as long as you give appropriate credit to the original author(s) and the source, provide a link to the Creative Commons licence, and indicate if changes were made. The images or other third party material in this article are included in the article's Creative Commons licence, unless indicated otherwise in a credit line to the material. If material is not included in the article's Creative Commons licence and your intended use is not permitted by statutory regulation or exceeds the permitted use, you will need to obtain permission directly from the copyright holder. To view a copy of this licence, visit http://creativecommons.org/licenses/by/4.0/. 
Many classes of enzymes have been involved in the joint damage that occurs in established RA. The family of matrix metalloproteinases (MMPs) is perhaps the most studied. They trigger the degradation of cartilage, bone, and tendons. Cytokines, known to be expressed in RA synovial tissues, are potent activators of MMPs genes [6].

Early initiation of disease modifying anti-rheumatic drugs (DMARDs) helps to reduce long-term disability but there are major adverse reactions associated with their use [7]. The use of biological agents has contributed remarkably to reductions in disease activity and structural damage. However, studies highlighted the potential for adverse effects with these agents, particularly the risk of infection and latent tuberculosis activation besides the high cost of these medications [8]. Thus, decision-making in prescribing medications for RA patients is encountered to many factors including the patient's preferences, economic status, and comorbidities.

Tetracyclines have a regulatory effect on the immune system and pathway to inflammation. They result in a decline in TNF- $\alpha$, IL-2, and IFN- $\gamma$ production and reduce $\mathrm{T}$ cell response to IL-2 suppressing their proliferation [9]. Tetracyclines also inhibit MMPs and suppress hydrolases like $\alpha$-amylases and phospholipase A2 [10, 11]. Tetracyclines also can downregulate gene expression and salvage the action of oxygen species which play a part in procollagenases and progelatinases activation in vitro [12].

Synthetic tetracyclines, like minocycline and doxycycline, display improved pharmacokinetic properties over first-generation tetracyclines as they are rapidly and fully absorbed with longer half-life [13]. Evidence from randomized studies [14-20] and a meta-analysis [21] have shown that minocycline has a beneficial effect in RA patients mainly on laboratory parameters with moderate clinical results. Minocycline was not included in the ACR 2015 guideline for RA therapy due to its infrequent usage and the lack of strong evidence for its effect [7]. Minocycline use was associated with hyperpigmentation and dizziness so, other studies [22-26] used an alternative tetracycline, doxycycline to overcome these adverse events and in a trial to reduce the cost.

Doxycycline has shown to be a powerful MMPs inhibitor also it suppresses in vitro migration of vascular smooth muscle cells [27]. Doxycycline also modulates many cellular functions such as cellular proliferation and matrix remodeling [28]. However, reports about doxycycline in RA therapy were inconsistent. Two trials showing no treatment effect in established RA [22, 23] while another study of early RA patients found significant improvement compared to placebo when used in combination with methotrexate [26].
Studies involving doxycycline were either carried out on a small number of patients $[24,25]$ or only on those having early disease [26]. Though studies showed that minocycline and doxycycline can represent treatment options for RA, rheumatology experts did not adopt them to be first-line choices for RA or restrict their use in refractory disease [29]. In this study, we aimed to reevaluate doxycycline as a cost-effective option for combination with methotrexate to improve its efficacy. This study was conducted on a large number of RA patients with either early or established disease.

\section{Methods}

\section{The study design}

The present study is a single-center unblinded randomized clinical trial conducted in a university-affiliated hospital from October 1, 2019, to February 20, 2020 (NCT03194204 ClinicalTrials.gov). It was designed to enroll 160 patients with RA who satisfied the ACR/ EULAR classification criteria in 2010 [30] and were attending the rheumatology outpatient clinic of Internal Medicine Department.

\section{Inclusion criteria}

Adult patients (' 18 years) with active seropositive RA, either early ( $\leq 6$ months) or established ( $>6$ months) disease [7]. Disease activity was defined as low, moderate, or high according to DAS28-CRP values calculated for each patient.

\section{Exclusion criteria}

Patients who had liver disease, renal disease, leucopenia, or thrombocytopenia; pregnant females or who were planning to become pregnant; those who were on unstable doses of oral corticosteroids or more than $5 \mathrm{mg} /$ day; and if they were allergic to MTX or tetracycline.

\section{Ethics approval}

This study was performed in line with the principles of the Declaration of Helsinki. The Committee of Medical Ethics of the Faculty of Medicine has approved the protocol for the study under number 17200080 .

\section{Informed consent}

Informed written consent was obtained from all individual participants included in the study after thorough discussion and explanation of possible adverse outcomes.

\section{Randomization}

Subjects were assigned in a 1:1 ratio randomly into one of two treatment arms; one group was maintained on MTX and the other group on MTX together with doxycycline orally $200 \mathrm{mg}$ daily. Study medications were given concomitant with the lowest baseline steroid dose 
(not more than $5 \mathrm{mg}$ ). MTX was started at a dose of 7.5 $\mathrm{mg} /$ week that was up-titrated each month according to DAS28-CRP till achieving the target or reaching the maximum tolerated dose. Patients who were on higher doses of MTX than $7.5 \mathrm{mg}$ at the beginning of the study continued on the same starting dose and followed up accordingly. Patients who were taking non-steroidal antiinflammatory drugs (NSAIDs) at stable doses were allowed to continue on them. Folic acid was given (5$10 \mathrm{mg} /$ week orally) concomitantly. Permuted BLOCK randomization was performed online using Research Randomizer (www.randomizer.org) to balance the treatment arms.

\section{Pre-treatment evaluation}

Clinical assessment included detailed history about disease onset, coarse, and duration; physical examination; and assessing DAS28-CRP to estimate the activity of RA [31]. Laboratory investigations performed at baseline in the following manner: Eight milliliters of blood were withdrawn by venipuncture and distributed into two tubes. Two milliliters placed in an EDTA tube for complete blood count (CBC) done using automated hematology analyzers and 6 $\mathrm{ml}$ in a plastic tube which was allowed to clot to separate serum. Non-hemolyzed serum was separated by centrifugation and part was used for the determination of blood urea, serum creatinine, liver function tests (albumin, aspartate transaminase (AST), alanine transaminase (ALT)), ESR done by the Westergren method, and CRP by latexenhanced nephelometry. Rheumatoid factor (RF IgM) was done by BN ProSpec, Siemens using ELISA assay, with the upper limit of normal 12 units (IU/ml). Anti-cyclic citrullinated peptide (Anti-CCP) was determined using the ELISA assay done by the Architect 1000R with the normal upper limit 5 units $/ \mathrm{ml}$. Conventional radiographs of both hands, wrists, and feet were done at baseline. All radiographs were scored based on Larsen's scoring system [32].

\section{Follow-up and post-treatment assessment}

Follow-up was done in the outpatient clinic every month for 3 consecutive months till the end of the study. In each visit, patients were assessed clinically to monitor disease status and adjust doses of the drugs taken accordingly based on treat to target strategy. This assessment also included asking about any side effects of the study drugs. Evaluation of adverse events was done by Common Terminology Criteria for Adverse Events (CTCAE) version 5.0 [33]. Clinical response, ESR, CRP, and DAS28-CRP after treatment were re-assessed at the end of the study.

\section{Sample size calculation}

G*Power 3.1.9.2 software program was utilized for the sample size calculation. The trial was planned to have
$85 \%$ power to recognize the difference between the study groups and $\alpha$ was 0.05 . It was supposed that the response rate in the group treated with MTX plus doxycycline was $75 \%$ and $50 \%$ at the MTX only group. This resulted in a sample size of 74 patients in each treatment arm. A drop rate of $9 \%$ was considered so we determined a total sample size of 160 patients (80 in each group).

\section{The study endpoint}

The primary outcome was the efficacy of the study drug based on the percentage of patients accomplishing remission or at least low activity (in those who had high or moderate disease activity) assessed by DAS28-CRP and the safety of doxycycline as adjuvant therapy.

\section{Statistical analysis}

Analysis of the results was done by Statistical Package for the Social Sciences (SPSS) program windows, version 24.0. Results were reported as percentages or mean \pm standard deviation (SD), medians, and interquartile ranges (IQR) according to normality of data. The normal distribution of data was tested using the Shapiro-Wilk test. A comparison of patients' properties was performed by the chi-squared test for categorical variables and the independent $t$ test when the variables were continuous. A comparison of variables before and after treatment was done by the paired $t$ test. Pearson's correlation coefficients were evaluated to demonstrate associations among variables. For all tests, $p$ values $<0.05$ were considered significant.

\section{Results}

Two hundred patients who attended the AUH rheumatology outpatient clinic were screened for the trial, and 40 patients were excluded from them for different causes as illustrated in the CONSORT flow chart (Fig. 1). There was a dropout rate of $7.5 \%$ mainly due to noncompliance and loss of follow-up.

The female to male ratio in the study's subjects was 15:1. The age of the trial's population ranged between 27 to 58 years and the range of their disease duration was 6 weeks up to 10 years. There were 20 (12.5\%) with low disease activity, $67(41.8 \%)$ had a moderate activity of the disease, and $73(45 \%)$ had high RA activity as assessed by DAS28-CRP. The rest of the clinical and demographic data are shown in Table 1.

The results of baseline laboratory and radiological investigations for the study subjects are shown in Table 2.

Baseline characteristics were compared between the trial groups after randomization regarding the disease duration, age, and DAS28-CRP. There were no statistical differences in the medians of age $(p=0.8)$, disease duration $(p=0.07)$, and DAS28-CRP $(p=0.67)$ of the study subjects in both treatment arms. Demographic data, 


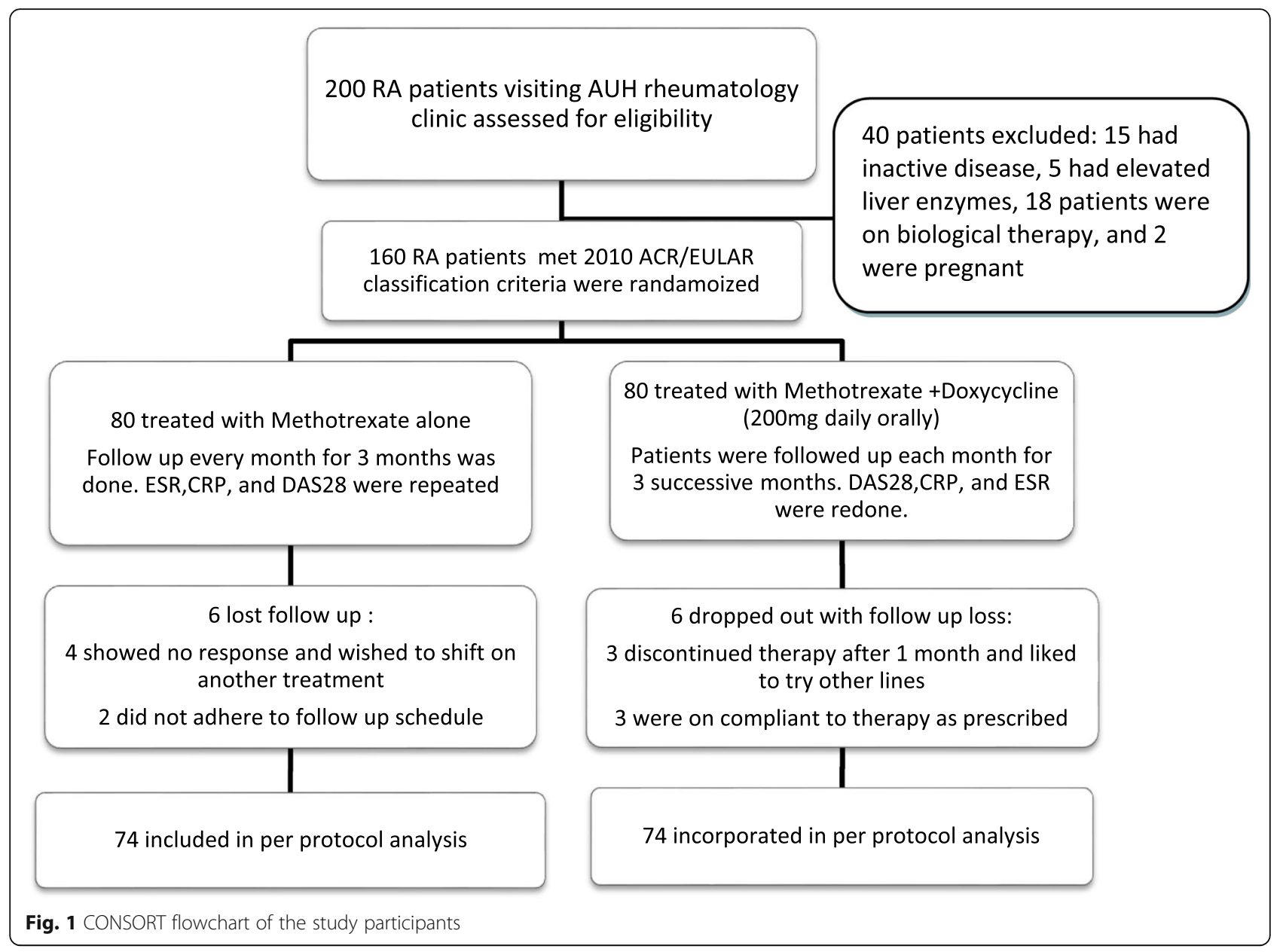

drug demographics, and Larsen score for each group are showed in Table 3.

In the group of patients treated with MTX only, there was a statistically significant difference in medians of DAS28-CRP after therapy ( $p=0.001)$ as a notable number of patients improved achieving remission (13.5\%) and low disease activity (4.1\%). There was a statistically significant difference $(p=0.001)$ when the medians of CRP were compared before (19.5) and after therapy (12). Medians of ESR (67 before and 54 after therapy) also showed statistically significant lower values after MTX treatment $(p=0.001)$.

In the patients treated with doxycycline in combination with MTX, the median of DAS28-CRP score showed a statistically significant difference after treatment $(p=0.001)$. High number of patients reached the target in the form of accomplishing remission (40.5\%) or low activity of the disease (29.7\%).

Comparing ESR and CRP medians at baseline (56 and 16 , respectively) to those after treatment (26 and 9, respectively) showed statistically significant lower levels after treatment $(p=0.001)$.
DAS28-CRP medians were statistically different between the trial groups $(p=0.005)$ as a significant number of patients treated with doxycycline reached lower DAS28-CRP compared to those treated with MTX only. A significant difference was detected among the group of patients managed with MTX together with doxycycline compared to the group treated with MTX as regard ESR $(p=0.005)$ and CRP $(p=0.003)$ with lower levels achieved in those treated with doxycycline in combination with MTX. Comparison of DAS28-CRP, ESR, and CRP medians between the group of patients treated with MTX alone and those treated with MTX combined with doxycycline after the 3 months follow up are showed in Table 4. Figure 2 comparatively illustrates the percentages of patients in different DAS28-CRP categories in response to the two treatment arms of the study.

Among those who responded to therapy (attained remission or low disease activity) in the group of patients treated with doxycycline with MTX, 18 (34.6\%) had early RA with a mean \pm SD of achieved DAS28-CRP score $2.69 \pm 0.57$ and $34(65.4 \%)$ had established RA with a 
Table 1 Demographic and clinical data of the studied patients

\begin{tabular}{ll}
\hline Variables & Total studied cases $(\mathbf{N}=\mathbf{1 6 0})$ \\
\hline Sex & $10(6.3 \%)$ \\
Male & $150(93.7 \%)$ \\
Female & \\
Age (years) & $46(41-52)$ \\
$\quad$ Median (IQR) & \\
Disease duration (years) & $4(1-6)$ \\
Median (IQR) & \\
Disease duration classification & $39(24.4 \%)$ \\
Early ( $\mathbf{6}$ months) & $121(75.6 \%)$ \\
Established (<6 months) & \\
Deformities & $12(7.5 \%)$ \\
Present & $148(92.5 \%)$ \\
$\quad$ Absent & \\
Rheumatoid nodules & $18(11.3 \%)$ \\
Present & $142(88.7 \%)$ \\
Absent & $16(10 \%)$ \\
Extra-articular manifestations & 10 \\
Interstitial lung disease & 2 \\
Pericardial effusion & $2.8(3.9-6)$ \\
Sjogren's syndrome & \\
Small vessel vasculitis & \\
Median (IQR) & \\
Range & \\
\hline DAS28 Disase actity score & \\
\hline
\end{tabular}

DAS28 Disease activity score in 28 joints, CRP C-reactive protein, $S D$ standard deviation, IQR interquartile range

Table 2 laboratory and radiological results of the studied cases

\begin{tabular}{ll}
\hline Variables & Median (IQR) \\
\hline Rheumatoid factor $(\mathrm{IU} / \mathrm{ml})$ & $72(38-108)$ \\
Anti-CCP $(\mathrm{IU} / \mathrm{ml})$ & $71(58-95.7)$ \\
ESR $(\mathrm{mm} / \mathrm{h})$ & $63(45-95)$ \\
CRP $(\mathrm{mg} / \mathrm{l})$ & $18(12.3-21.7)$ \\
ALT $(\mathrm{U} / \mathrm{L})$ & $29(25-35)$ \\
AST $(\mathrm{U} / \mathrm{L})$ & $26.5(23-31)$ \\
Albumin $(\mathrm{g} / \mathrm{l})$ & $33(29-36)$ \\
WBCs $\left(\times 10^{9} / \mathrm{L}\right)$ & $10(7.8-12)$ \\
Hemoglobin $(\mathrm{HB})(\mathrm{g} / \mathrm{dl})$ & $11(10-12)$ \\
Platelets $(\mathrm{Plt})\left(\times 10^{9} / \mathrm{L}\right)$ & $384(300.7-460)$ \\
Urea $(\mathrm{mmol} / \mathrm{l})$ & $5(4.5-6)$ \\
Creatinine $(\mu \mathrm{mol} / \mathrm{l})$ & $63.5(56-75.7)$ \\
Larsen score & $20(10.5-38.75)$ \\
\hline AntiCCPAnticyclic
\end{tabular}

Anti-CCP Anti-cyclic citrullinated peptide, ESR erythrocyte sedimentation rate, $C R P$ C-reactive protein, ALT alanine transaminase, AST aspartate transaminase, $W B C s$ white blood cells mean \pm SD DAS28-CRP $2.54 \pm 0.37$. There was no statistically significant difference among responders between mean DAS28-CRP in patients with early and those with established disease $(p=0.26)$.

Fourteen (19.2\%) patients treated with doxycycline developed side effects mainly gastrointestinal and dermatological which were evaluated using CTCAE. Seven patients had nausea grade I, three others had nausea grade II, two patients developed vomiting grade I, and two patients had grade I pruritus but all did not suffer any long-term sequelae or hospitalization.

The mean dose of MTX the patients used in the third month at the end of the study was calculated. In those who received MTX only as a DMARD, it was $18 \pm 3.5$ while it was $16.2 \pm 2.9$ for patients given doxycycline together with MTX. There was a statistically significant difference in the means of MTX dose between the two groups $(p=0.001)$. Among the patients managed with MTX alone, it was noticed that higher number of patients developed methotrexate-related side effects as they needed higher doses of MTX. Five patients developed grade I neutropenia that was asymptomatic and controlled by lowering the dose, four developed oral ulcers, and eight patients had mild elevations of liver enzymes that lead to a reduction of doses but neither needed stopping the drug. The doses of MTX for those who developed side effects ranged between 22.5 and $25 \mathrm{mg} /$ week. Three of those patients were on $25 \mathrm{mg} /$ week and fourteen were on $22.5 \mathrm{mg} /$ week. During follow up, patients treated with doxycycline together with MTX did not need to increase the dose of MTX as their disease activity was controlled on lower doses of MTX compared to those treated with MTX alone.

\section{Discussion}

The latest minocycline and doxycycline studies in RA coincided with the appearance of biological therapies. Antibiotics are usually viewed as late in the management of the disease after all conventional therapies fail. Besides that, the possible contribution of oral filamentous bacteria in RA pathogenesis can renew interest in the therapeutic role of antibiotics [34, 35].

With established efficacy proven for non-biologic and biologic DMARDs in RA, it is questionable that tetracyclines may have a position in the treatment of RA. However, studies proved that they do have a potentially important role. Indeed, they may prove to be a safer and more cost-effective alternative to some of the newer agents especially in low-resource areas.

In this work, we used doxycycline $(200 \mathrm{mg} /$ day orally) for either early or established active RA together with MTX; our results showed that a better response rate with lower levels of inflammatory markers were achieved in doxycycline-treated subjects compared to MTX alone. 
Table 3 Demographic data and radiological results of the two study groups before treatment

\begin{tabular}{|c|c|c|c|}
\hline \multirow[t]{2}{*}{ Variables } & \multicolumn{2}{|c|}{ Number, percentage, median (IQR) } & \multirow{2}{*}{$\begin{array}{l}P \\
\text { value }\end{array}$} \\
\hline & MTX only group $(n=80)$ & MTX and doxycycline group $(n=80)$ & \\
\hline Age (years) & $47(42.3-52.8)$ & $46(39.25-52)$ & 0.8 \\
\hline Disease duration (years) & $4.5(2-6)$ & $4(0.5-5.75)$ & 0.079 \\
\hline \multicolumn{4}{|c|}{ Disease duration classification } \\
\hline Early ( $\leq 6$ months) & $15(18.8 \%)$ & $24(30 \%)$ & \multirow[t]{2}{*}{0.09} \\
\hline Established (<6 months) & $65(81.3 \%)$ & $56(70 \%)$ & \\
\hline \multicolumn{4}{|l|}{ Sex } \\
\hline Male & $2(2.5 \%)$ & $8(10 \%)$ & \multirow[t]{2}{*}{0.06} \\
\hline Female & 78 (97.5\%) & $72(90 \%)$ & \\
\hline \multicolumn{4}{|l|}{ NSAIDs users } \\
\hline Yes & $58(72.5 \%)$ & $50(62.5 \%)$ & \multirow[t]{2}{*}{0.177} \\
\hline No & $22(27.5 \%)$ & $30(37.5 \%)$ & \\
\hline \multicolumn{4}{|l|}{ Steroids users } \\
\hline Yes & $28(35 \%)$ & $32(40 \%)$ & \multirow[t]{2}{*}{0.514} \\
\hline No & $52(65 \%)$ & $48(60 \%)$ & \\
\hline \multicolumn{4}{|l|}{ DAS28 categories } \\
\hline Remission & 0 & 0 & \multirow[t]{4}{*}{0.98} \\
\hline Mild & $10(12.5 \%)$ & $10(12.5 \%)$ & \\
\hline Moderate & $34(42.5 \%)$ & $33(41.3 \%)$ & \\
\hline High & $36(45 \%)$ & 37 (46.3\%) & \\
\hline DAS28-CRP & $4.9(3.8-6.4)$ & $4.9(3.8-5.6)$ & 0.67 \\
\hline Larsen score & $20(12-38.5)$ & $20(8-38.75)$ & 0.6 \\
\hline
\end{tabular}

IQR interquartile range, MTX methotrexate, NSAIDs non-steroidal anti-inflammatory drugs, DAS28 Disease activity score, CRP C-reactive protein

Table 4 Comparison between MTX-treated and MTX with doxycycline-treated patient groups after 3 months therapy

\begin{tabular}{|c|c|c|c|}
\hline \multirow[t]{2}{*}{ Variables } & \multicolumn{2}{|c|}{ Median (IQR), number (percentage) } & \multirow{2}{*}{$\begin{array}{l}P \\
\text { value }\end{array}$} \\
\hline & After MTX $(n=74)$ & After MTX plus doxycycline $(n=74)$ & \\
\hline DAS28-CRP & $4.2(3.6-5)$ & $2.8(2.3-3.5)$ & 0.005 \\
\hline \multicolumn{4}{|c|}{ DAS28-CRP categories } \\
\hline Remission & $10(13.5 \%)$ & $30(40.5 \%)$ & \multirow[t]{4}{*}{0.005} \\
\hline Low & $3(4.1 \%)$ & $22(29.7 \%)$ & \\
\hline Moderate & $50(67.6 \%)$ & $22(29.7 \%)$ & \\
\hline High & $11(14.9 \%)$ & 0 & \\
\hline $\operatorname{ESR}(\mathrm{mm} / \mathrm{h})$ & $54(36-76)$ & $26(9.7-38)$ & 0.005 \\
\hline \multicolumn{4}{|l|}{ ESR } \\
\hline Normal & $10(13.5 \%)$ & $24(32.4 \%)$ & \multirow[t]{2}{*}{0.006} \\
\hline Abnormal & $64(86.5 \%)$ & $50(67.6 \%)$ & \\
\hline CRP (mg/l) & $12(9-16)$ & $9(3-13)$ & 0.003 \\
\hline \multicolumn{4}{|l|}{ CRP } \\
\hline Normal & $6(8.1 \%)$ & $18(24.3 \%)$ & \multirow[t]{2}{*}{0.007} \\
\hline Abnormal & 68 (91.9\%) & 56 (75.7\%) & \\
\hline
\end{tabular}




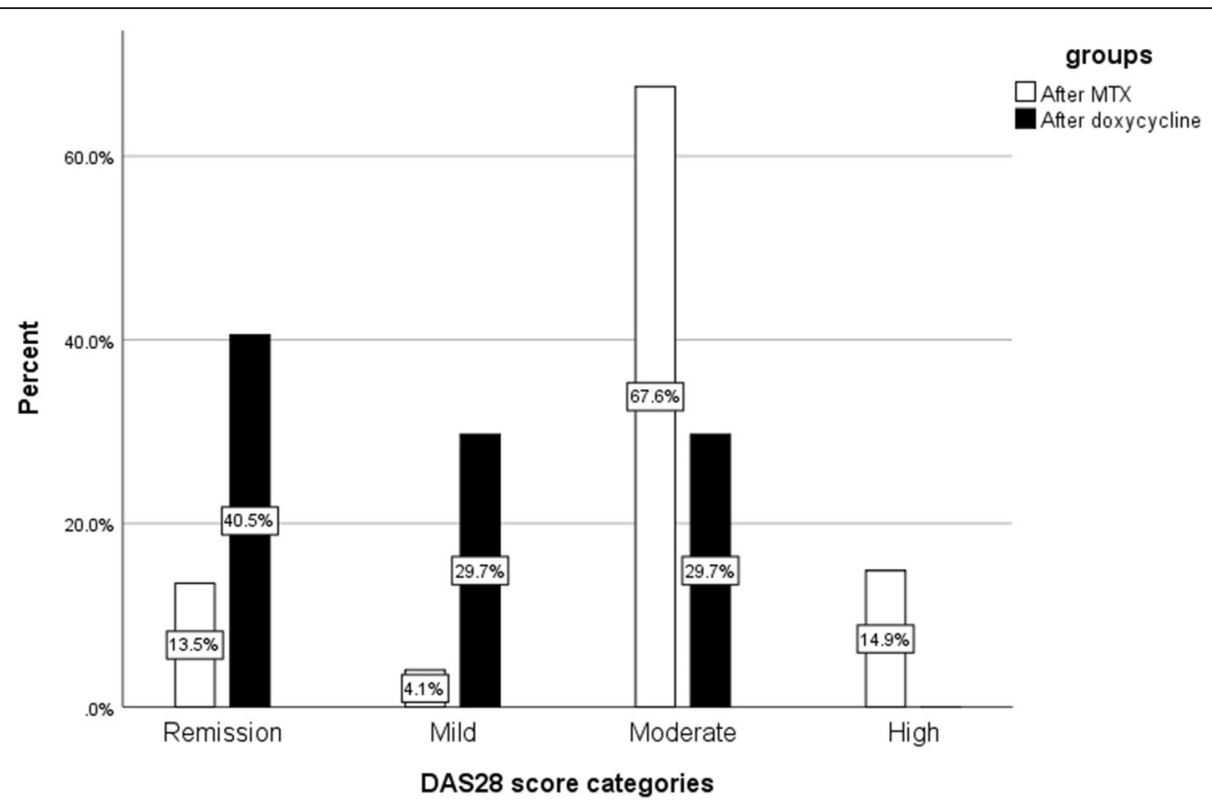

Fig. 2 Percentages of patients in different DAS28-CRP categories after treatment in both the two groups (patients treated with MTX and patients treated with MTX and doxycycline)

In our work, doxycycline was effective in both early and established RA. This may be explained by the result of a study that compared samples of synovial tissue from patients with RA of less than 1 year with samples from RA patients with a disease duration of more than 5 years. Synovial hyperplasia was more marked in patients with known illness; however, synovial inflammation did not vary between the two classes [36]. Thus, the equal response to doxycycline in early and established disease regarding disease activity and influence on the inflammatory markers can be strongly related to its antiinflammatory effect as synovial inflammation is a common feature in both early and established RA.

Some trials that studied doxycycline yielded excellent results. A study of O'Dell et al compared the effectiveness of doxycycline when added to MTX versus the use of MTX only in early seropositive RA therapy and showed that treatment with MTX together with doxycycline was better than treatment with MTX alone [26]. The therapeutic responses to both high and low doses of doxycycline were equivalent indicating that the antimetalloproteinase effects of doxycycline were more significant than the antibacterial effects. Also, a metaanalysis by Stone et al. has proved the usefulness of minocycline and doxycycline as therapeutic options for RA as they led to significant clinical improvement in RA activity without an increase in adverse effects [21].

However, results from previous studies were not encouraging which may be mainly attributed to the design and the type of patients in these studies. Results of a placebo-controlled doxycycline trial [22] in which doxycycline (50 mg orally twice per day) was compared versus placebo showed that there was no therapeutic benefit of doxycycline in patients with established illness. However, in that study, patients were on different DMARDs (including azathioprine, antimalarials, sulfasalazine, and MTX) which have unequal efficacy in RA treatment and doxycycline was used in a crossover manner. Two studies used intravenous (IV) doxycycline in established RA patients but did not show any benefits of the use of doxycycline. Explanation to this may be the limited number of patients in these studies and that the treatment period was short which may not allowed adequate time for response besides the lower dose of doxycycline than in our study [23, 24]. It is therefore not possible to completely rule out a beneficial effect for IV doxycycline over placebo. A small pilot prospective study done on 29 patients [25] compared doxycycline to MTX. It showed similar findings for the treatment of RA patients with doxycycline or MTX as all measures of disease activity improved after 6 months of therapy in both groups but that difference was not statistically significant between MTX and doxycycline.

The current study showed that doxycycline is well tolerated in general, despite concerns about drug toxicity. The reported side effects were of mild severity mainly gastrointestinal and skin side effects. None of the patients stopped doxycycline because of the side effects. In the group of patients treated with MTX alone, it was noticed that a higher number of patients developed methotrexate-related side effects as they needed higher doses of MTX. 
Our clinical trial was conducted on a large number of seropositive RA either early or established disease. Limitations to our study was the short duration as longer duration of therapy is needed to test the ability of doxycycline to achieve persistent remission when used in combination with MTX and to detect any long-term side effects. The lake of blindness was another limitation. We did not compare doxycycline to other DMARDs as we aimed to improve the efficacy of MTX, which is the standard treatment for RA, by adding doxycycline. However, it is recommended to carry out studies that compare doxycycline with other commonly used DMARDs as it proved to ameliorate MTX efficacy.

\section{Conclusion}

Doxycycline showed to have additive or multiplicative effects to the standard RA therapy, methotrexate. It should be viewed as an alternative for combination therapy with methotrexate and as a safe option for patients who are cautious to try multiple conventional or biological therapies or unable to afford them.

\section{Acknowledgements}

Not applicable.

\section{Authors' contributions}

SSE and HSE designed the study, critically revised the work, and approved the final version. EMI collected the data and analyzed and interpreted them. AAM performed the lab work. SMA performed radiological studies and interpreted them. All authors have read and approved the manuscript.

\section{Funding}

The present work was sponsored by the Faculty of Medicine's research grant office, Assiut University. The grant number was 013-29/6/2016.

\section{Availability of data and materials}

The datasets used and/or analyzed during the current study are available from the corresponding author on reasonable request.

\section{Ethics approval and consent to participate}

The protocol of this study was approved by The Committee of Medical Ethics of the Faculty of Medicine, Assiut University, under number 17200080. Informed written consent was obtained from all individual participants included in the study.

\section{Consent for publication}

Not applicable.

\section{Competing interests}

The authors declare that they have no competing interests.

\section{Author details}

${ }^{1}$ Department of Internal Medicine, Rheumatology Unit, Faculty of Medicine, Assiut University, Assiut, Egypt. ${ }^{2}$ Clinical Pathology Department, Faculty of Medicine, Assiut University, Assiut, Egypt. ${ }^{3}$ Diagnostic Radiology Department, Faculty of Medicine, Assiut University, Assiut, Egypt.

Received: 4 November 2020 Accepted: 7 January 2021

Published online: 20 January 2021

\section{References}

1. Buch M, Emery P (2009) The aetiology and pathogenesis of rheumatoid arthritis. Pharm J 9:5-10
2. Snir O, Widhe M, Hermansson M, von Spee C, Lindberg J, Hensen S et al (2010) Antibodies to several citrullinated antigens are enriched in the joints of rheumatoid arthritis patients. Arthritis Rheum 62:44-52

3. Baeten D, Steenbakkers PG, Rijnders AM, Boots AM, Veys EM, De Keyser F (2004) Detection of major histocompatibility complex/human cartilage gp39 complexes in rheumatoid arthritis synovitis as a specific and independent histologic marker. Arthritis Rheum 50:444-451

4. De Groof A, Ducreux J, Humby F, Toukap AN, Badot V, Pitzalis C et al (2016) Higher expression of TNFa-induced genes in the synovium of patients with early rheumatoid arthritis correlates with disease activity, and predicts absence of response to first line therapy. Arthritis Res Ther 18:19

5. Gracie JA, Forsey RJ, Chan WL, Gilmour A, Leung BP, Greer MR et al (1999) A proinflammatory role for IL-18 in rheumatoid arthritis. J Clin Invest 104: 1393-1401

6. Malemud CJ (2017) Matrix metalloproteinases and synovial joint pathology. Prog Mol Biol Transl Sci: Elsevier 148:305-325

7. Singh JA, Saag KG, Bridges SL Jr, Akl EA, Bannuru RR, Sullivan MC et al (2016) 2015 American College of Rheumatology guideline for the treatment of rheumatoid arthritis. Arthritis Rheumatol 68:1-26

8. Keane J, Gershon S, Wise RP, Mirabile-Levens E, Kasznica J, Schwieterman WD et al (2001) Tuberculosis associated with infliximab, a tumor necrosis factor a-neutralizing agent. N Engl J Med 345:1098-1104

9. Kloppenburg M, Verweij CL, Miltenburg AM, Verhoeven AJ, Daha MR, Dijkmans BA et al (1995) The influence of tetracyclines on T cell activation. Clin Exp Immunol 102:635-641

10. Dorman G, Cseh S, Hajdu I, Barna L, Konya D, Kupai K et al (2010) Matrix metalloproteinase inhibitors: a critical appraisal of design principles and proposed therapeutic utility. Drugs 70:949-964

11. Bahrami F, Morris DL, Pourgholami MH (2012) Tetracyclines: drugs with huge therapeutic potential. Mini Rev Med Chem 12:44-52

12. Ramamurthy NS, Vernillo AT, Greenwald RA, Lee HM, Sorsa T, Golub LM et al (1993) Reactive oxygen species activate and tetracyclines inhibit rat osteoblast collagenase. J Bone Miner Res 8:1247-1253

13. Klein NC, Cunha BA (1995) Tetracyclines. Med Clin North Am 79:789-80

14. Breedveld FC, Dijkmans BA, Mattie H (1990) Minocycline treatment for rheumatoid arthritis: an open dose finding study. J Rheumatol 17:43-46

15. Langevitz P, Bank I, Zemer D, Book M, Pras M (1992) Treatment of resistant rheumatoid arthritis with minocycline: an open study. J Rheumatol 19:1502-1504

16. Kloppenburg M, Breedveld FC, Terwiel JP, Mallee C, Dijkmans BA (1994) Minocycline in active rheumatoid arthritis. A double-blind, placebocontrolled trial. Arthritis Rheum 37:629-636

17. Tilley BC, Alarcon GS, Heyse SP, Trentham DE, Neuner R, Kaplan DA et al (1995) Minocycline in rheumatoid arthritis. A 48-week, double-blind, placebo-controlled trial. MIRA Trial Group. Ann Intern Med 122:81-89

18. O'Dell JR, Haire CE, Palmer W, Drymalski W, Wees S, Blakely K et al (1997) Treatment of early rheumatoid arthritis with minocycline or placebo: results of a randomized, double-blind, placebo-controlled trial. Arthritis Rheum 40: 842-848

19. O'Dell JR, Paulsen G, Haire CE, Blakely K, Palmer W, Wees S et al (1999) Treatment of early seropositive rheumatoid arthritis with minocycline: fouryear followup of a double-blind, placebo-controlled trial. Arthritis Rheum 42: 1691-1695

20. O'Dell JR, Blakely KW, Mallek JA, Eckhoff PJ, Leff RD, Wees SJ et al (2001) Treatment of early seropositive rheumatoid arthritis: a two-year, doubleblind comparison of minocycline and hydroxychloroquine. Arthritis Rheum 44:2235-2241

21. Stone M, Fortin PR, Pacheco-Tena C, Inman RD (2003) Should tetracycline treatment be used more extensively for rheumatoid arthritis? Metaanalysis demonstrates clinical benefit with reduction in disease activity. J Rheumatol 30:2112-2122

22. van der Laan W, Molenaar E, Ronday K, Verheijen J, Breedveld F, Greenwald $R$ et al (2001) Lack of effect of doxycycline on disease activity and joint damage in patients with rheumatoid arthritis. A double blind, placebo controlled trial. J Rheumatol 28:1967-1974

23. St Clair EW, Wilkinson WE, Pisetsky DS, Sexton DJ, Drew R, Kraus VB et al (2001) The effects of intravenous doxycycline therapy for rheumatoid arthritis: a randomized, double-blind, placebo-controlled trial. Arthritis Rheum 44:1043-1047

24. Pillemer S, Gulko P, Ligier S, Yarboro C, Gourley M, Goldbach-Mansky R et al (2003) Pilot clinical trial of intravenous doxycycline versus placebo for rheumatoid arthritis. J Rheumatol 30:41-43 
25. Sreekanth VR, Handa R, Wali JP, Aggarwal P, Dwivedi SN (2000) Doxycycline in the treatment of rheumatoid arthritis--a pilot study. J Assoc Physicians India 48:804-807

26. O'Dell JR, Elliott JR, Mallek JA, Mikuls TR, Weaver CA, Glickstein S et al (2006) Treatment of early seropositive rheumatoid arthritis: doxycycline plus methotrexate versus methotrexate alone. Arthritis Rheum 54:621-627

27. Mountain DJ, Kirkpatrick SS, Arnold JD, Buckley MR, McNally MM, Stevens SL et al (2019) The efficacy of systemic doxycycline administration as an inhibitor of intimal hyperplasia after balloon angioplasty arterial injury. Ann Vasc Surg 57:201-209

28. Franco C, Ho B, Mulholland D, Hou G, Islam M, Donaldson K et al (2006) Doxycycline alters vascular smooth muscle cell adhesion, migration, and reorganization of fibrillar collagen matrices. Am J Pathol 168:1697-1709

29. Smith CJ, Sayles H, Mikuls TR, Michaud K (2011) Minocycline and doxycycline therapy in community patients with rheumatoid arthritis: prescribing patterns, patient-level determinants of use, and patient-reported side effects. Arthritis Res Ther 13:R168

30. Aletaha D, Neogi T, Silman AJ, Funovits J, Felson DT, Bingham CO III et al (2010) 2010 Rheumatoid arthritis classification criteria: an American College of Rheumatology/European League Against Rheumatism collaborative initiative. Arthritis Rheum 62:2569-2581

31. Singh JA, Furst DE, Bharat A, Curtis JR, Kavanaugh AF, Kremer JM et al (2012) 2012 update of the 2008 American College of Rheumatology recommendations for the use of disease-modifying antirheumatic drugs and biologic agents in the treatment of rheumatoid arthritis. Arthritis Care Res (Hoboken) 64:625-639

32. Larsen A (1995) How to apply Larsen score in evaluating radiographs of rheumatoid arthritis in long-term studies. J Rheumatol 22:1974-1975

33. National Cancer Institute. Common Terminology Criteria for Adverse Events (CTCAE) v. 5, 2017.

34. Hitchon CA, Chandad F, Ferucci ED, Willemze A, loan-Facsinay A, van der Woude D et al (2010) Antibodies to Porphyromonas gingivalis are associated with anticitrullinated protein antibodies in patients with rheumatoid arthritis and their relatives. J Rheumatol 37:1105-1112

35. Wegner N, Wait R, Sroka A, Eick S, Nguyen KA, Lundberg K et al (2010) Peptidylarginine deiminase from Porphyromonas gingivalis citrullinates human fibrinogen and alpha-enolase: implications for autoimmunity in rheumatoid arthritis. Arthritis Rheum 62:2662-2672

36. Tak PP, Thurkow EW, Daha MR, Kluin PM, Smeets TJ, Meinders AE et al (1995) Expression of adhesion molecules in early rheumatoid synovial tissue. Clin Immunol Immunopathol 77:236-242

\section{Publisher's Note}

Springer Nature remains neutral with regard to jurisdictional claims in published maps and institutional affiliations.

\section{Submit your manuscript to a SpringerOpen ${ }^{\circ}$ journal and benefit from:}

- Convenient online submission

- Rigorous peer review

- Open access: articles freely available online

- High visibility within the field

- Retaining the copyright to your article

Submit your next manuscript at $\boldsymbol{\nabla}$ springeropen.com 